\title{
Studies on Structural and Conducting Properties of Goethite Nanoparticles Doped HPMC Polymer Films
}

\author{
Thejas Gopal Krishne Urs, Mahadevaiah Dasaiah, and Rudrappa Somashekar \\ Department of Physics, University of Mysore, Manasagangotri, Mysore 570006, India \\ Correspondence should be addressed to Rudrappa Somashekar; rs@physics.uni-mysore.ac.in
}

Received 21 January 2014; Accepted 18 March 2014; Published 8 April 2014

Academic Editor: Yeong-Soon Gal

Copyright (c) 2014 Thejas Gopal Krishne Urs et al. This is an open access article distributed under the Creative Commons Attribution License, which permits unrestricted use, distribution, and reproduction in any medium, provided the original work is properly cited.

\begin{abstract}
We have carried out systematic studies on Goethite nanoparticles doped (dispersed) HPMC polymer films to quantify the changes in their structural properties, the conductivity, and IR absorbance of films. It is observed that the addition of nanoparticles has significant influence on changing structural parameters and hence enhancing the conductivity of the polymer composite considerably. These polymer composites are water soluble.
\end{abstract}

\section{Introduction}

Recent works have focused on the designed synthesis and exploration of applications of binary oxide films, such as $\mathrm{TiO}_{2}-\mathrm{CeO}_{2}[1], \mathrm{TiO}_{2}-\mathrm{ZnO}[2], \mathrm{TiO}_{2}-\mathrm{SiO}_{2}$, and $\mathrm{TiO}_{2}-\mathrm{WO}_{3}$ [3]. These were considered to be effective semiconductor, advanced materials, heterogeneous catalysts, and catalyst supports. The nanoparticles doped polymers have wide applications in devices transducers, gas sensors, and as catalysts [4-6]. This is expected as they are inexpensive. The properties of the materials are found to vary with their constituents. There are several methods of preparation of nanoparticles, which we dope to the polymer matrix and among them hydrothermal approach $[7,8]$ has great advantages. Nanoparticles doped polymers have created a great interest in the field of research and our work is based on the preparation of a new material to the class of polymer nanocomposites. We have used hydroxypropyl methylcellulose (HPMC) as the polymer base in this work, which is a water soluble polymer and is widely used in the field of medicine due to its solubility in water and high inertness, possessing a nontoxic nature. It is mainly used in manufacturing of capsules due to its property of controlled drug release $[9,10]$. It is easily accepted and has a variety of viscosities and types of substitution, and the necessary doses are easy to formulate [11]. HPMC is a potential biodegradable cellulose derivative that produces films with good oil barrier and excellent mechanical properties and it is tasteless. The addition of nanoparticles to a polymer changes the structural and other properties like conductivity and IR absorbance considerably from its parent polymer. In this paper we report preparation of materials and characterization studies using X-ray, conductivity, and FT-IR techniques.

\section{Preparation}

2.1. Preparation of Nanoparticles. The hydrothermal technique has been the best technique to prepare Goethite $(\mathrm{FeO}(\mathrm{OH}))$ particles of desired sizes with homogeneity in composition and high degree crystallinity. Goethite $(\mathrm{FeO}(\mathrm{OH}))$ nanoparticles were prepared with $1 \%$ to $5 \%$ weight of Goethite and were tested for their photodegradation efficiency. The synthesis has been carried out using Morey autoclaves (designed and fabricated at the Department of Environmental Science, University of Mysore, Mysore) provided with Teflon liners. The conditions selected for the synthesis of Goethite particles are at temperature of $T=200^{\circ} \mathrm{C}$ and a pressure less than 50 bars. The starting material $\mathrm{FeCl}_{3}$ was taken in a Teflon liner. A required amount of an effective mineralizer was added to the mixture. The mixture is stirred thoroughly to obtain a homogenous and relatively viscous solution. The Teflon liner is placed in an 
autoclave and then the autoclaves were placed in the oven and kept at a predetermined temperature for a desired period (12-72 hrs). The mineralizer used was $1 \mathrm{M} \mathrm{NaOH}$. After the experimental runs the autoclaves were quenched and the liner is taken out. The contents of the liner are thoroughly washed in double distilled water repeatedly which is later dried in an oven $\left(\right.$ at $40^{\circ} \mathrm{C}$ ) before using it for the study. The precursors were prepared using double distilled water. It is one of the thermodynamically most stable iron oxides at ambient temperatures and it is, for this reason, often found as an end product of many transformations.

2.2. Preparation of the Polymer Nanocomposites. The nanoparticles doped polymer films are prepared by solution casting method. The HPMC solution of 5\% was prepared at room temperature and, for this, the different proportions of $0.01,0.02$, and 0.03 grams of Goethite are added in the separate beakers containing HPMC pure solutions of the same amount and were stirred for around 1 hour each and then it was poured into glass plates and allowed to cast for desired number of days. A pure HPMC film was also prepared in the same procedure for comparative studies.

\section{Experimental}

3.1. XRD Recording. The casted polymer films were cut into desired pieces of required size $(2 \mathrm{~cm} \times 2 \mathrm{~cm})$ and were taken in the sample holder of Rigaku-Denki miniflex II desktop $\mathrm{X}$-Ray diffractometer with the settings of $30 \mathrm{kV}$ and $15 \mathrm{~mA}$, scanning rate of $5^{\circ}$ per minute, and for the range of $5^{\circ}$ to $40^{\circ}$ with step size of $0.02^{\circ}$ being recorded. The integral breadth of the diffraction peaks is related to the apparent size of the crystals and to their microstrains. If the size and strain broadening exist simultaneously, then crystallite size and strain can be calculated by Williamson-Hall plot (W-H plot). For relative comparison of the parameters, W$\mathrm{H}$ plot is a reasonably reliable one [12]. The W-H plot considers both limited size of the crystals and the presence of crystallographic distortions which leads to Lorentzian intensity distributions. The slope of the $\mathrm{W}-\mathrm{H}$ plot represents the average strain in the crystal, whereas intercept with the $y$-axis gives the crystallite size. The Williamson-Hall relation is given by

$$
\beta \frac{\cos \theta}{\lambda}=\frac{1}{D}+4 \varepsilon \frac{\sin \theta}{\lambda}
$$

where " $\beta$ " is the full width at half maximum (FWHM) of the peak measured in radians, " $D$ " is average crystallite size, and " $\varepsilon$ " is average lattice strain. The obtained XRD plots and the values of crystallite size and average strain are given in Figure 1 and Table 1, respectively.

3.2. Conductivity. The conductivity measurements of samples were determined by using HIOKI LCR-Hi tester 353250 model available. Our samples were taken in the sample holder provided in the instrument. This instrument gives the transconductance $(G)$ of the sample which is dependent on

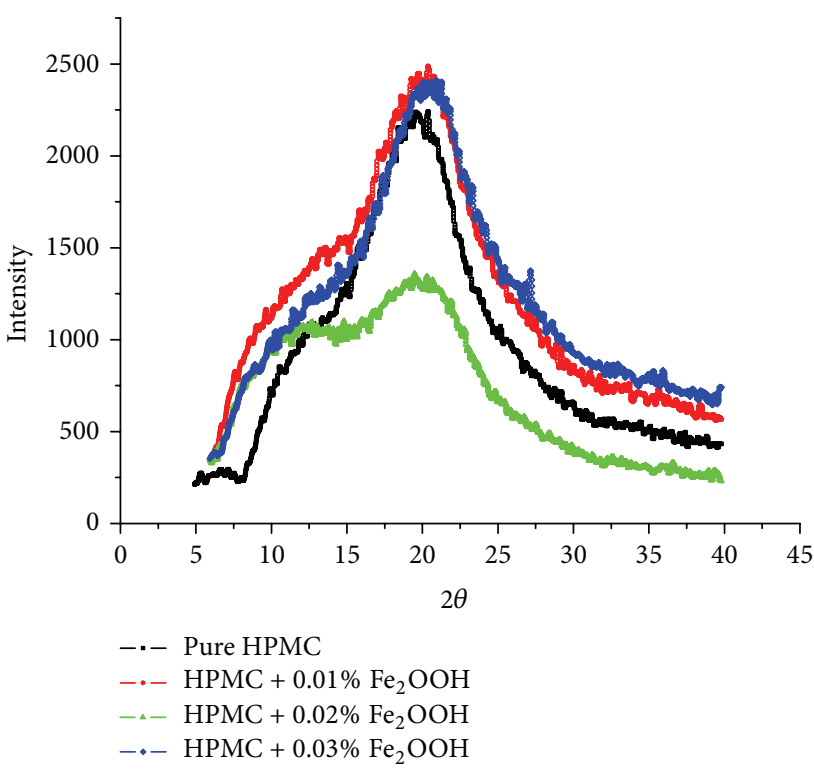

FIgURE 1: The consolidated XRD plots of pure HMPC and Goethite nanoparticles doped HPMC polymers.

TABLE 1: W-H plot results from the obtained XRD pattern.

\begin{tabular}{lcc}
\hline Samples & Crystallite size $(\AA)$ & Percentage strain \\
\hline Pure & 11.44 & 1.90 \\
0.01 & 10.04 & 4.48 \\
0.02 & 11.41 & 1.51 \\
0.03 & 15.51 & 6.16 \\
\hline
\end{tabular}

its thickness and the area. The conductivity $(\sigma)$ of the sample can be obtained by the relation,

$$
\sigma=\frac{t * G}{A},
$$

where " $t$ " is the thickness and " $A$ " is the area of the sample.

This instrument gives the transconductance values for different frequencies from $50 \mathrm{~Hz}$ to $5 \mathrm{MHz}$. The obtained transconductance values for various frequencies were evaluated to get the conductivity results for the same corresponding frequencies and a graph of conductivity for various frequencies was plotted as a function of its concentration.

This plot and tabulation are shown in Figure 2 and Table 2, respectively. At $1 \mathrm{kHz}$, the variation of conductivity with dopant is given in Figure 3.

3.3. FT-IR. The FT-IR spectrum for these composites was recorded using JASCO FT-IR 4100 type A instrument, for the scanning range from $4000 \mathrm{~cm}^{-1}$ to $400 \mathrm{~cm}^{-1}$. The infrared spectrum taken for pure HPMC and Goethite doped HPMC polymers is given in Figure 5.

\section{Results}

It is evident from Table 1 that the average crystallite size of the pure HPMC is found to decrease first with the 
TABLE 2: Conductivity values of the samples at different AC frequencies.

\begin{tabular}{lcccc}
\hline \multirow{2}{*}{ Samples } & \multicolumn{4}{c}{ Conductivity $\sigma$ in $\mathrm{Sm}^{-1}\left(\times 10^{-6}\right)$} \\
& $1 \mathrm{kHz}$ & $10 \mathrm{kHz}$ & $100 \mathrm{kHz}$ & $1 \mathrm{MHz}$ \\
\hline Pure HPMC & 0.062 & 0.175 & 7.84 & 4.65 \\
$0.01 \%$ Goethite: HPMC & 9.63 & 19.2 & 23.5 & 28.1 \\
$0.02 \%$ Goethite: HPMC & 18.5 & 47.6 & 95.1 & 139.0 \\
$0.03 \%$ Goethite: HPMC & 18.6 & 47.8 & 92.9 & 137.0 \\
\hline
\end{tabular}

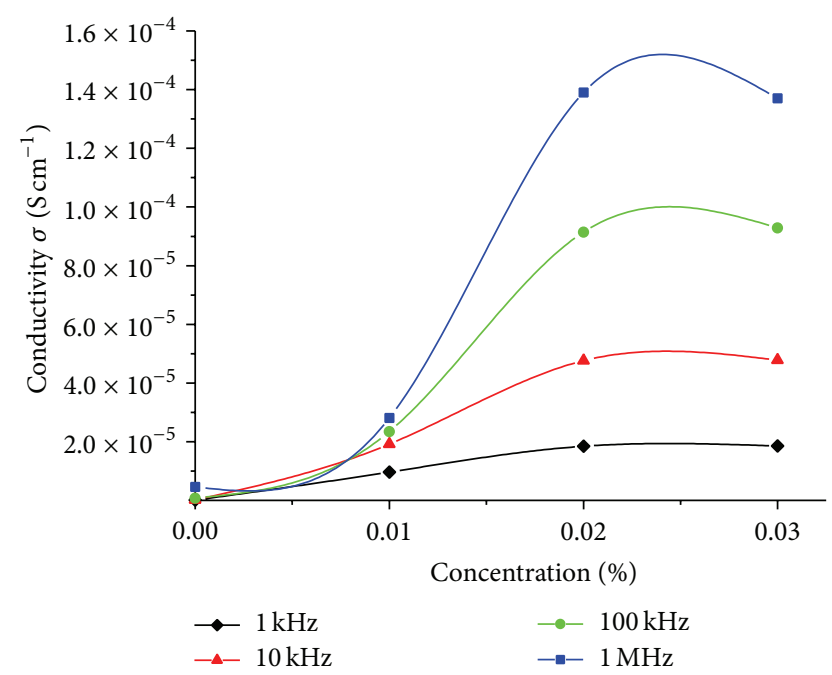

Figure 2: The plot of ionic conductivity of the pure HPMC and Goethite nanoparticles doped HPMC polymers for various frequencies as a function of its concentration.

dopant concentration of $0.01 \%$ but later it increases with the concentration of Goethite nanoparticles. This is because the addition of nanoparticles to the polymer matrix affects the total crystallite size of the parent polymer, but later the crystallite size of the nanoparticles adds up with the overall crystallite size resulting in the increase of composite crystallite size with the concentration. It is seen that this variation makes an interesting change in conducting property of the polymer composite. The variation of crystallinity with dopant is given in Figure 4. The total strain in the crystal is due to the mismatch between the material and the substrate and other crystallographic defects that may be present in the crystal.

For pure HPMC polymer sample, 3 reflections were considered which were centered at 13.06, 19.67, and 25.47 on the $2 \theta$ axis; for these corresponding $\theta$ values, $d_{h k l}$ was calculated using Bragg's equation and by the relation for monoclinic crystal lattices; that is,

$$
\frac{1}{d_{h k l}^{2}}=\frac{h^{2}}{a^{2} \sin ^{2} \beta}-\frac{2 h l \cos \beta}{a^{2} \sin ^{2} \beta}+\frac{l^{2}}{c^{2} \sin \beta}+\frac{k^{2}}{b^{2}} .
$$

The respective $h, k, l$ values were determined. Here $\lambda$ is the wavelength of X-ray, " $a$ " is $0.787 \mathrm{~nm}$, " $b$ " is $0.817 \mathrm{~nm}$, " $c$ " is $1.034 \mathrm{~nm}$, and " $\beta$ " is $96.3^{\circ}$, which are the parameters of cellulose [13]. Leonardi et al. have reported that the crystallite

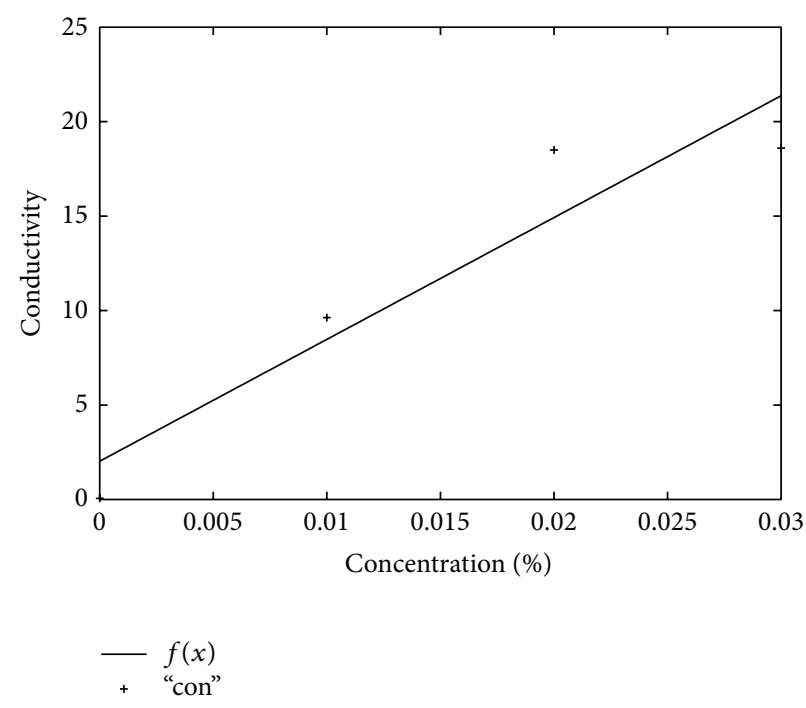

FIGURE 3: The plot of conductivity as a function of dopant concentration.

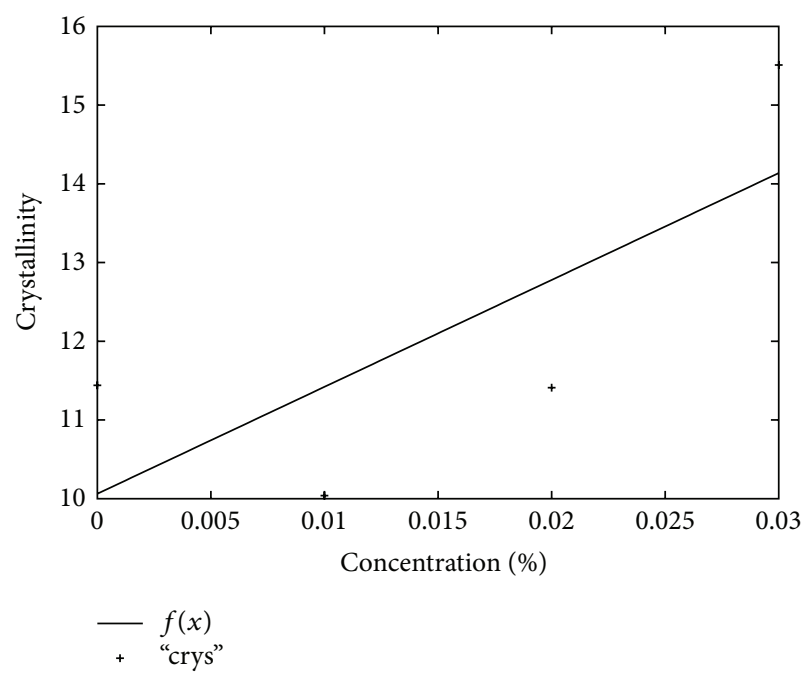

FIgURE 4: The variation of crystallinity as a function of dopant concentration.

size is different along different Bragg angles [14]; considering this and taking all the above stated parameters and Bragg's reflections, an attempt was done to sketch crystallite shape of pure HPMC polymer showing all three reflections along with unit cell crystallite in Figure 6.

The conductivity of HPMC pure film has been enhanced with the addition of Goethite nanoparticles and is significantly high for the concentration of $0.02 \%$ but on an average conductivity increases with the increase in dopant percentage. Plot of conductivity versus concentration for various frequencies is shown in Figure 2, which shows the respective increase in the conducting property of HPMC polymer with increase in its concentration.

From the FT-IR spectrum we have studied the nature of chemical bonds in polymers that can be studied through 


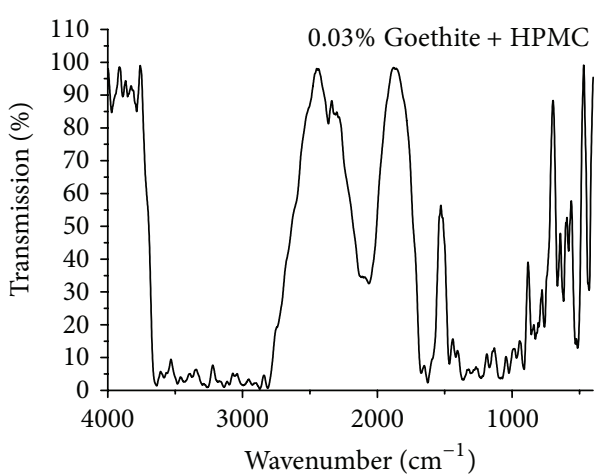

(a)

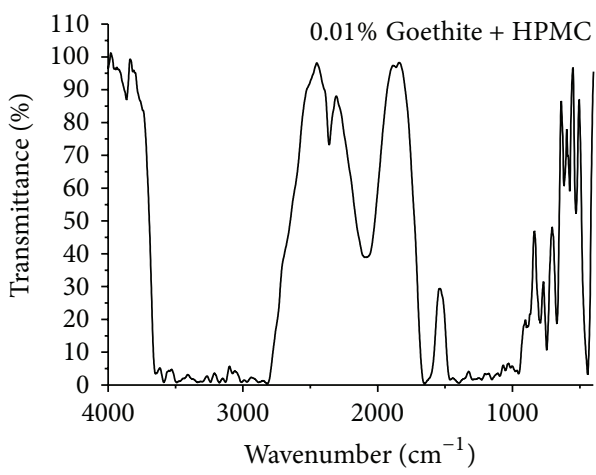

(c)

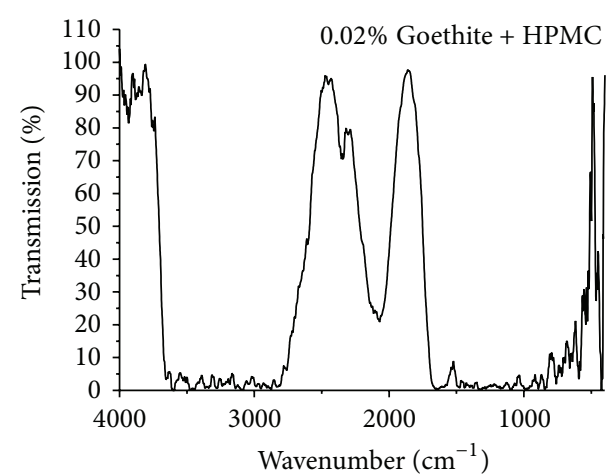

(b)

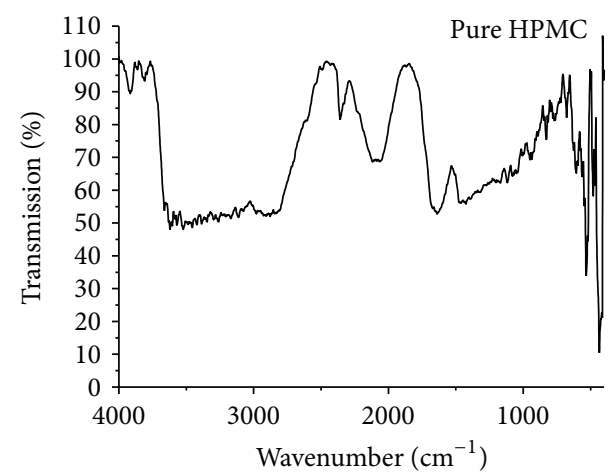

(d)

FIGURE 5: IR spectrum obtained for the pure HPMC and Goethite nanoparticles doped HPMC polymers and Goethite nanoparticles doped HPMC polymers.

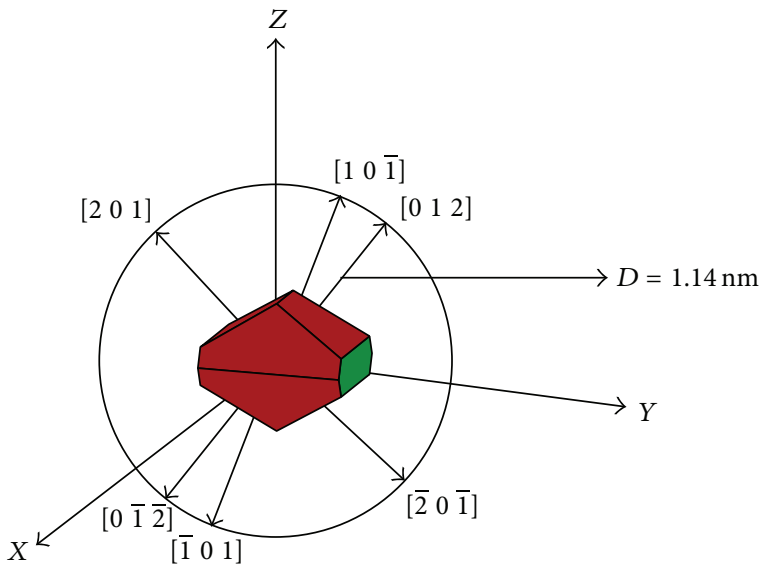

FIGURE 6: Unit cell crystallite shape with crystallite size along different Bragg angles.

the characterization of the vibration modes by infrared spectroscopy [15]. We have calculated few parameters such as equilibrium vibration frequency $\left(\bar{v}_{e}\right)$, anharmonicity constant, fundamental and first overtone transition frequencies, zero point energy, and force constant of $\mathrm{O}-\mathrm{H}$ stretch. For pure HPMC the fundamental and first overtone transitions of $\mathrm{O}-\mathrm{H}$ bonds are centered at $3620 \mathrm{~cm}^{-1}$ and $2117.5 \mathrm{~cm}^{-1}$, respectively. The equilibrium vibration frequency of the chain about this bond is calculated by solving the equations given below [16].

For the pure HPMC polymer:

Frequency of the fundamental transition

$$
\bar{v}_{e}\left(1-2 \chi_{e}\right)=2117.5 .
$$

Frequency of the first overtone

$$
2 \bar{v}_{e}\left(1-3 \chi_{e}\right)=3620.7
$$

The obtained equilibrium vibration " $\bar{v}_{e}$ " for pure HPMC is $2731.68 \mathrm{~cm}^{-1}$. In the same manner the equilibrium vibration for all the other samples was calculated.

The zero-point energy is given by the following relation:

$$
\varepsilon_{0}=\frac{\bar{v}_{e}}{2\left(1-\chi_{e} / 2\right)},
$$

where $\bar{v}_{e}$ is the equilibrium vibration and $\chi_{e}$ is the anharmonicity constant.

The force constant is calculated using the relation

$$
k=4 \pi^{2} \mu c^{2} \bar{v}_{e}^{2},
$$

where " $\mu$ " is the reduced mass of the system, " $c$ " is the light velocity, and " $\bar{v}_{e}$ " is equilibrium vibration frequency. 
TABLE 3: IR parameters calculated.

\begin{tabular}{lcccccc}
\hline Samples & $\begin{array}{c}\text { Fundamental transition } \\
\text { frequency }\left(\mathrm{cm}^{-1}\right)\end{array}$ & $\begin{array}{c}\text { First overtone } \\
\text { frequency }\left(\mathrm{cm}^{-1}\right)\end{array}$ & $\begin{array}{c}\text { Equilibrium vibration } \\
\text { frequency } \bar{v}_{e}\left(\mathrm{~cm}^{-1}\right)\end{array}$ & $\begin{array}{c}\text { Anharmonicity } \\
\text { constant } \chi_{e}\end{array}$ & $\begin{array}{c}\text { Zero-point energy } \\
\varepsilon_{0}\left(\mathrm{~cm}^{-1}\right)\end{array}$ & $\begin{array}{c}\text { Force constant “ } K \text { " } \\
(\mathrm{N} / \mathrm{m})\end{array}$ \\
\hline Pure & 2117.46 & 3620.7 & 2731.68 & $11.2 \times 10^{-2}$ & 1289.35 & 412.65 \\
$0.01 \%$ & 2096.24 & 3587.91 & 2700.81 & $11.2 \times 10^{-2}$ & 1274.7 & 403.37 \\
$0.02 \%$ & 2071.17 & 3604.30 & 2609.21 & $10.3 \times 10^{-2}$ & 1236.76 & 376.42 \\
$0.03 \%$ & 2062.5 & 3618.76 & 2568.74 & $9.85 \times 10^{-2}$ & 1220.15 & 364.89 \\
\hline
\end{tabular}

Using all these equations the IR spectrum parameters which were quoted before were calculated and tabulated in Table 3. From these results it is evident that the force constant between $\mathrm{O}-\mathrm{H}$ bond is found to be decreased with increase in dopant concentration and also the zero-point energy $\varepsilon_{0}$ is also found shifted towards the lower frequency with the increased dopant concentration. The anharmonicity constant $\chi_{e}$ and the equilibrium vibration frequency " $\bar{v}_{e}$ " do change in the same manner with respect to the dopant concentration. From this we can say that there are no such changes encountered in the structural properties of Goethite nanoparticles doped HPMC polymer as that found in the microstructural parameters such as crystallite size and strain calculated using WAXS data [15].

\section{Conclusions}

The conductivity of Goethite doped HPMC polymers has been increased with the increase in its concentration. But this increase in the conducting property of these doped polymers is not linear with the increase in the concentration of dopants. This nonlinearity in conducting property of Goethite: HPMC polymers is due to its crystallite size variation. The variation of crystallite sizes has been tabulated in Table 2 and shown in Figure 4. We have obtained the conductivity of pure HPMC at room temperature around $6.28 \times 10^{-6} \mathrm{Sm}^{-1}$ and the conductivity for doped ones $9.63 \times$ $10^{-4}$ to $1.86 \times 10^{-3} \mathrm{Sm}^{-1}$ which shows that the conductance of these doped HPMC polymers is more than that of silicon and conducting polymers like polythiophene and polyacetylene which possess a conductance in the range $4.3 \times 10^{-4}$ and $10^{-10}$ to $10^{-8} \mathrm{Sm}^{-1}$, respectively.

\section{Conflict of Interests}

The authors declare that there is no conflict of interests regarding the publication of this paper.

\section{Acknowledgments}

The authors thank UGC (University Grants Commission), India, for the grants under UPE (University with potential of Excellence) and CPEPA (Centre with potential for Excellence in particular area) research program for the University of Mysore, India.

\section{References}

[1] K. Nakagawa, Y. Murata, M. Kishida, M. Adachi, M. Hiro, and K. Susa, "Formation and reaction activity of $\mathrm{CeO}_{2}$ nanoparticles of cubic structure and various shaped $\mathrm{CeO}_{2}-\mathrm{TiO}_{2}$ composite nanostructures," Materials Chemistry and Physics, vol. 104, no. 1, pp. 30-39, 2007.

[2] K. H. Yoon, J. Cho, and D. H. Kang, "Synthesis and characterization of $\mathrm{TiO} 2-\mathrm{ZnO}$ nanocomposite by a two-step chemical method," Materials Research Bulletin, vol. 34, pp. 1451-1461, 1999.

[3] I. Shiyanovskaya and M. Hepel, "Bicomponent $\mathrm{WO}_{3} / \mathrm{TiO}_{3}$ films as photoelectrodes," Journal of the Electrochemical Society, vol. 146, no. 1, pp. 243-249, 1999.

[4] P. Q. Mantas and J. L. Baptista, "The barrier height formation in $\mathrm{ZnO}$ varistors," Journal of the European Ceramic Society, vol. 15, no. 7, pp. 605-615, 1995.

[5] F. C. M. van de Pol, F. R. Blom, and T. J. A. Popma, "R.f. planar magnetron sputtered $\mathrm{ZnO}$ films I: structural properties," Thin Solid Films, vol. 204, no. 2, pp. 349-364, 1991.

[6] M. J. Mayo, "Processing of nanocrystalline ceramics from ultrafine particles," International Materials Reviews, vol. 41, no. 3, pp. 85-115, 1996.

[7] L. Vayssieres, "Growth of arrayed nanorods and nanowires of $\mathrm{ZnO}$ from aqueous solutions," Advanced Materials, vol. 15, no. 5, pp. 464-466, 2003.

[8] M. Guo, P. Diao, and S. Cai, "Hydrothermal growth of wellaligned $\mathrm{ZnO}$ nanorod arrays: dependence of morphology and alignment ordering upon preparing conditions," Journal of Solid State Chemistry, vol. 178, no. 6, pp. 1864-1873, 2005.

[9] H. Konno, T. Handa, D. Alonzo, and L. Yaylor, "Effect of polymer type on the dissolution profile of amorphous solid dispersions containing felodipini," European Journal of Pharmaceutics and Biopharmaceutics, vol. 70, no. 2, pp. 493-499, 2008.

[10] E. Karavas, E. Georgarakis, and D. Bikiaris, "Application of PVP/HPMC miscible blends with enhanced mucoadhesive properties for adjusting drug release in predictable pulsatile chronotherapeutics," European Journal of Pharmaceutics and Biopharmaceutics, vol. 64, no. 1, pp. 115-126, 2006.

[11] H. McPhillips, D. Q. M. Craig, P. G. Royall, and V. L. Hill, "Characterisation of the glass transition of HPMC using modulated temperature differential scanning calorimetry," International Journal of Pharmaceutics, vol. 180, no. 1, pp. 83-90, 1999.

[12] J. I. Langford and D. Louër, "Powder diffraction," Reports on Progress in Physics, vol. 59, no. 2, article 131, 1996.

[13] O. M. Samir and R. Somashekar, "Intrinsic strain effect on crystal and molecular structure of (dch32) cotton fiber," Powder Diffraction, vol. 22, no. 1, pp. 20-26, 2007. 
[14] A. Leonardi, M. Leoni, S. Siboni, and P. Scardi, "Common volume functions and diffraction line profiles of polyhedral domains," Journal of Applied Crystallography, vol. 45, pp. 11621172,2012

[15] S. Sangappa, S. Asha, T. Demappa, G. Sanjeev, P. Parameswara, and R. Somashekar, "Spectroscopic and thermal studies of 8 $\mathrm{MeV}$ electron beam irradiated HPMC films," Nuclear Instruments and Methods in Physics Research. Section B: Beam Interactions with Materials and Atoms, vol. 267, no. 14, pp. 2385-2389, 2009.

[16] J. Davenas, X. L. Xu, G. Boiteux, and D. Sage, "Relation between structure and electronic properties of ion irradiated polymers," Nuclear Instruments and Methods in Physics Research B, vol. 39, no. 1-4, pp. 754-763, 1989. 

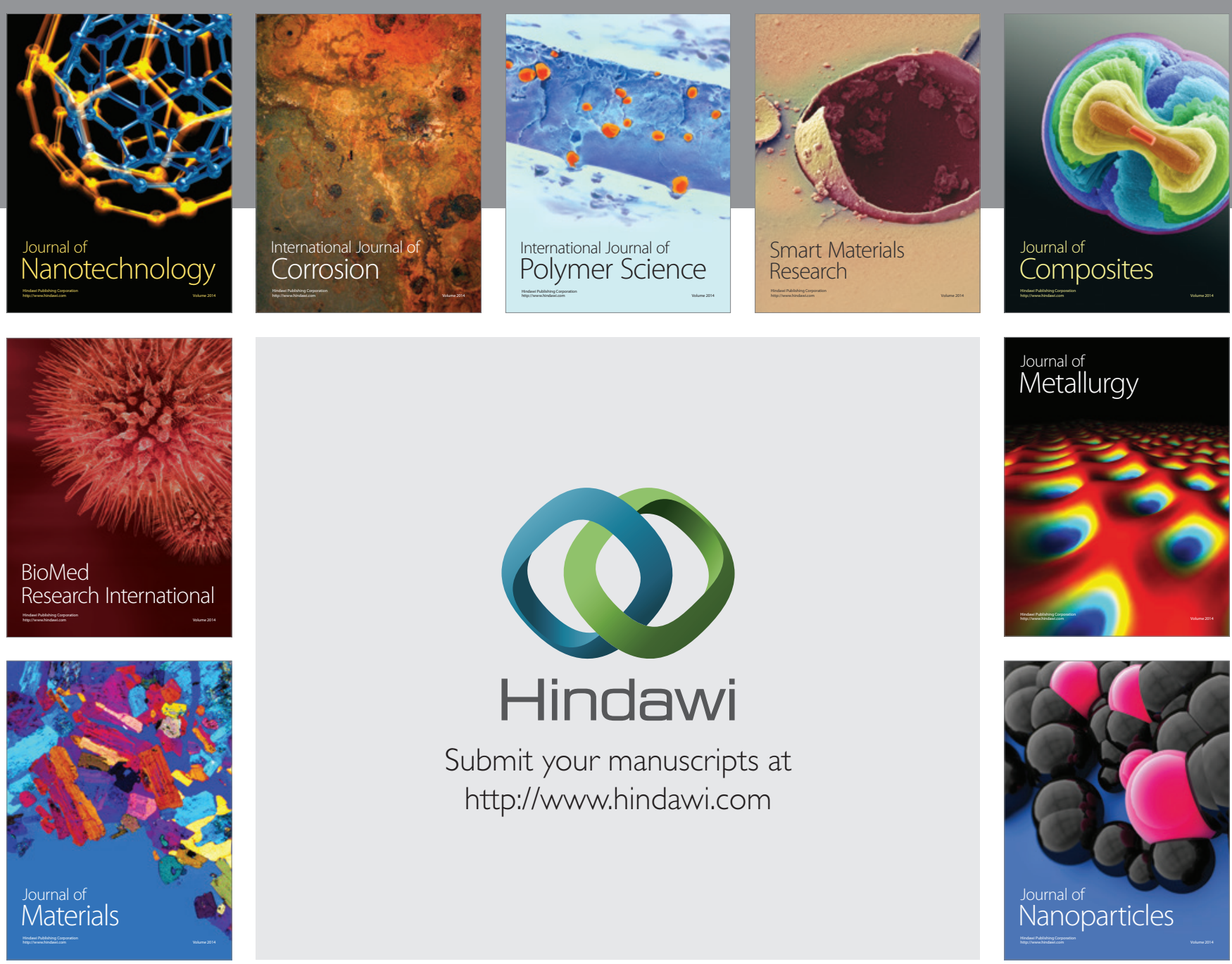

Submit your manuscripts at http://www.hindawi.com
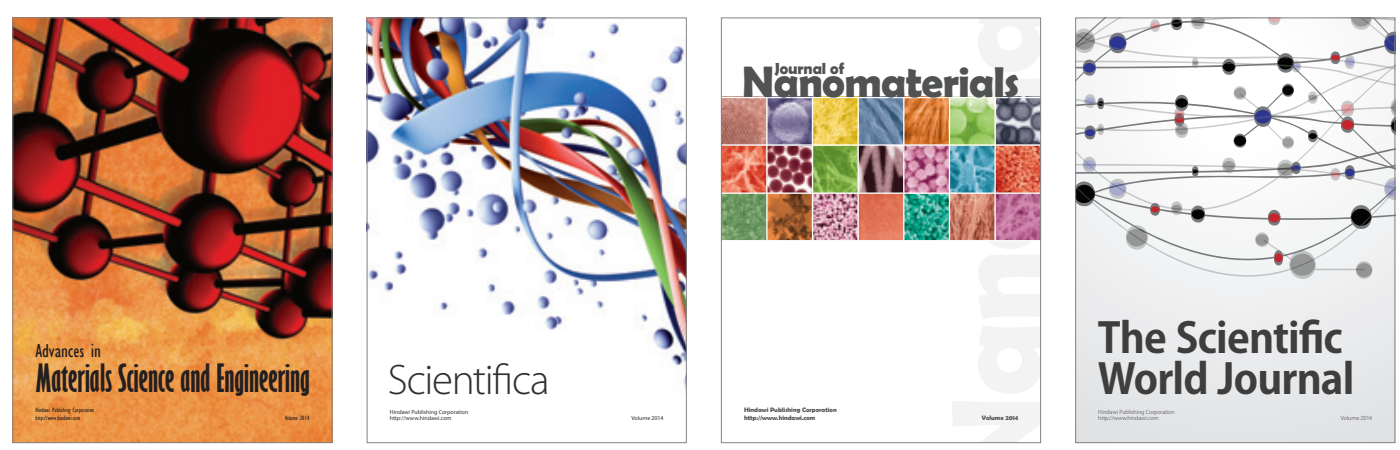

\section{The Scientific World Journal}
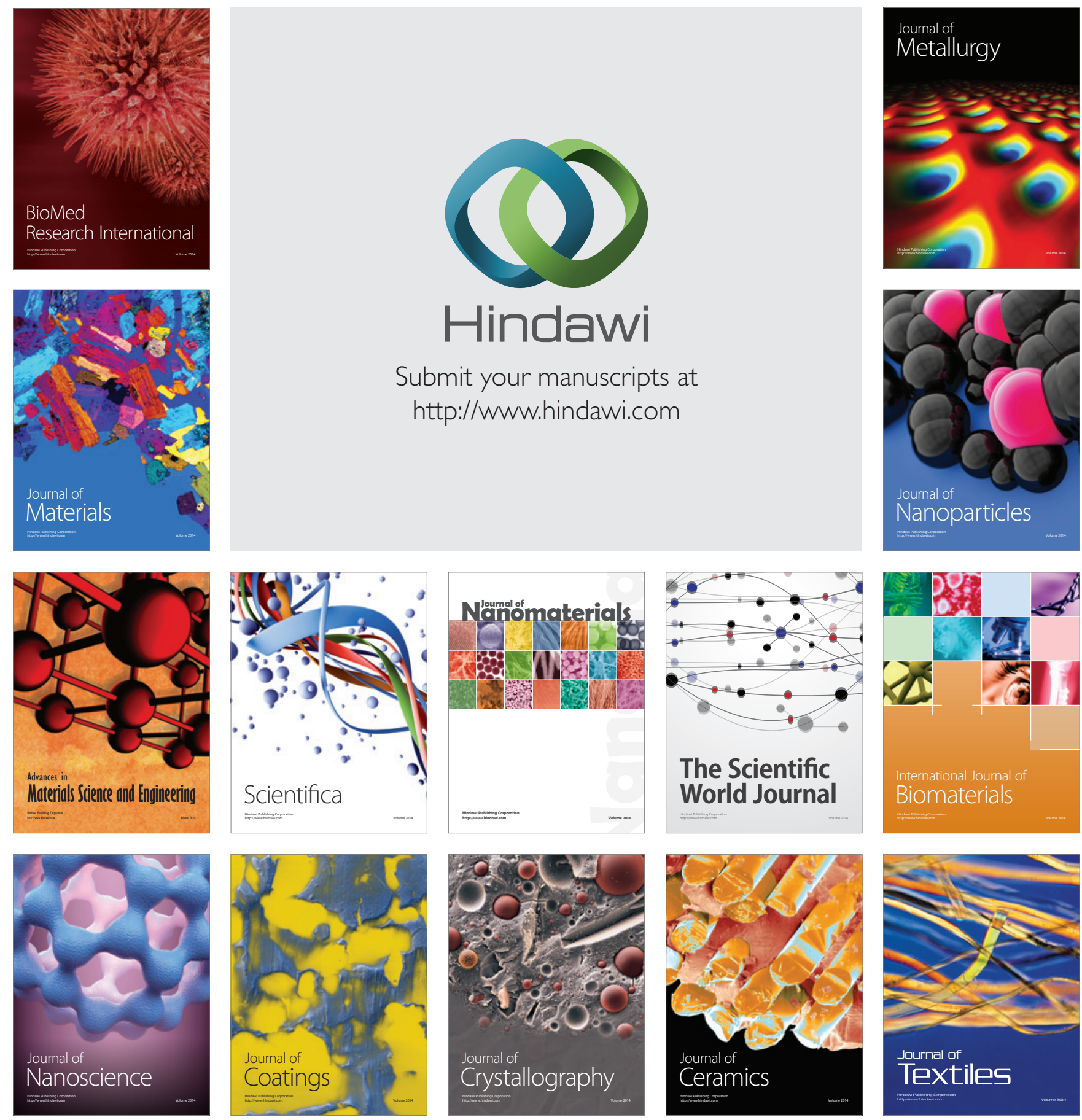